\title{
The impact of F-PEC scale and strategic planning in the family business
}

\author{
Nazanin Haji Mirza Hossein Yazdia ${ }^{*}$
}

${ }^{a}$ Department of Management and Accounting, South Tehran Branch, Islamic Azad University, Tehran, Iran

\begin{tabular}{l}
\hline C H R O N I C L E \\
\hline Article history: \\
Received January 9, 2017 \\
Received in revised format \\
January 112017 \\
Accepted May 222017 \\
Available online \\
May 242017 \\
\hline Keywords: \\
Family business \\
Culture \\
Power \\
Family experience \\
Strategic planning
\end{tabular}
\begin{abstract}
A B S T R A C T
Due to the thrive of family businesses in the current economic situation, to solve the problem of the definition of these businesses, in this paper we suggest using a scale that measures the quality of family influence through three dimensions: power, experience, and culture. The family influence on power, experience and culture (F-PEC) scale, as well as strategic planning, have been tested precisely using a random sample of more than 211 people from two companies of Golestan and Shemshal industrial group located in Tehran, Iran through using the confirmatory factor analysis technique. The Scale shows a high level of reliability. F-PEC has been used in a number of studies to theoretical development, particularly in terms of the impact of family influence on the individual resources and as a source of competitive advantage. In this research, strategic planning is also considered as a source of competitive advantage and its impact on the success of the family business has been investigated.
\end{abstract}

\section{Introduction}

During the past few years, family business has been considered as a separate academic discipline since the 1990s (Chua et al., 1999; Carlock \& Ward, 2001; Witt, 2003; Chrisman et al., 2003a, 2003b). Small family businesses do not just represent small scale economic activity but they are the outcome of entrepreneurial ambition and family involvement, which indicates that willpower and emotional commitment blend with calculative considerations (Johannisson \& Huse, 2000). According to Bird et al. (2002) and Flören (2002) "family business research is becoming increasingly sophisticated and rigorous". Anderson and Reeb (2003) studied the relationship between founding-family ownership and firm performance and reported that family ownership was prevalent and substantial. They also reported that family firms could perform better than non-family ones. The relationship between family holdings and business performance was considered to be nonlinear. Astrachan et al. (2002) developed an alternative technique for evaluating the extent of family influence on any firm, enabling the measurement of the effect of family on revenue components.

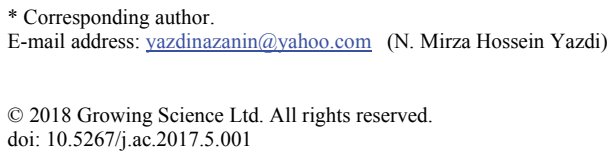


Birley and Pleitner (2001) reported the findings of a 16-country study on owner managers' behaviors in terms of both business and family decisions. Cabrera-Suárez et al. (2001) applied two theoretical methods from the strategic management field to investigate the critical process and analyzed how it could be managed efficiently. The conceptual framework provided an insight for understanding the nature and transfer of knowledge within the family business, which is a basis for developing competitive advantage over nonfamily businesses. Faccio and Lang (2002) analyzed the ultimate ownership and control of 5,232 business enterprises in 13 Western European countries. Widely held companies were believed to be more important in the UK and Ireland, while family controlled companies in continental Europe. Financial and large companies were more likely widely held, while non-financial and small companies were more likely family controlled. Heck and Scannell Trent (1999) presented U. S. prevalence data and their relationships to different family business definitions presented. The level of prevalence indicated an association with gender, ownership/management, involvement of family members, and generation of owner.

Johannisson and Huse (2000) investigated how contrasting ideologies influence on the selection process of outside directors in the small family business. Kayser and Wallau (2002) performed a survey in Germany and stated that although manufacturing family businesses maintain a rather small number of products due to their high degree of specialization, they export their products worldwide. Increasingly, the firms are intensifying their service orientation and going into cooperative relationships with other enterprises, even in sensitive strategic areas like research and development. They concluded that in spite of the continuing high ranking of values such as independence and maintaining the enterprise under the effect of the family, enterprises are open for cooperative activities within the firm (Klein \& Blondel, 2002). Stewart (2003) considered the expenses and advantages of a role for kinship in business.

\subsection{F-PEC scale of family influence}

There are at least three important dimensions of family influence: power, experience and culture. A common problem mentioned later that is not considered in the F-PEC is evaluation. Self-identification is not considered because the repeatability of such results is questionable at best. Power refers to the dominance exerted by financing businesses such as stocks held by the family and through leadership and/or control of the business through the management and/or participation in management by family.

Subcriteria of power include stock, the percentage of senior management positions and relative board positions retained by the family. Experience refers to the whole experience that family brings to the business and will be operational by the generation in the management employment and ownership. In fact, the more generations are in company, the more the chance of related familial memory. Culture, refers to the values and commitment and employs the family business commitment questionnaire. (Carlock \& Ward, 2001). Family commitment has been observed in the overlap between family and business values. Three dimensions of power, experience and culture of the F-PEC scale, constitute an indicator of the impact of family. (See Appendix 1 for a copy of F-PEC scale).

\section{2 power, ownership, administration and management}

Subscales of power in F-PEC scale consider the percentage of family members on the Board of Directors and the percentage of members that are on the board through family members. A family can affect business through the extent and quality of the ownership, administration and management participation. a measure should not taking into account only these issues, but it also should consider the legal, political and economic considerations related to different cultures (Whyte, 2003).

Since the early 1970s, family participation as leaders of family firms has been considered. This Research has focused on a number of different topics, including legitimate leadership, performance, 
the theory of principal-agent and government structures. Subscale of power in F-PEC evaluates the degree of influence or Total domination of family members. This level of influence can be seen through ownership, management and administration as changeable or additive, though, this is also an empirical question. Families influence through management and administration can be measured as a proportion of family members in board. In contrast, indirect effects could mean a board called the family members, but there is no family member in it. This type of indirect influence of family, can be substantial. To optimized assess of this effects, a weighting system should be used. Likely impact of a third party, such as a non-family member has a range from 0 to 100 percent. An outsider can be expected to have less impact than one of the family members, even if he/she is selected by the family desires. For example, a weak non-family member who works in a strong family environment, leaves half of his/her decision to family, which means that about 50 percent of family influence is exercised. Conversely, a strong non-family member in a poor family environment has much more personal impact. If someone aims to measure all of these direct impacts, we propose a conservative weighting of the indirect familial influence with the scale's lower limit of $10 \%$. Then considering the above views, the first hypothesis arises in this way:

Hypothesis 1: The family power affects the family business.

\subsection{Experience: generation in control of the family business}

Subscale of experience is related to succession and refers to the number of family members who have contribution in business. A number of scholars stated that when a company wishes to transfer to the next generation, can only be regarded as a family business. Others believe that at least a generation transition should occur. It may be argued that the level of experience that comes from a succession process is the highest from the first generation to the second. During the first generation of ownership, many provisions have been deployed. So the second and subsequent generations may add lesser value to this process. We point out that the experience of family business from succession can be seen as an exponential function. Accordingly, the generation of family ownership and who is governing the board of management dimensions weight based on the non-linear algorithms.

Hypothesis 2: Family Experience affects the family business.

\subsection{Culture, family values against business}

Family business culture is formed by the values that are rooted in an organization (Klein, 2000). The important individual values can be incorporated in the internal political issues, in the manner of communication, ways of dealing with conflict and the degree of business centralization versus its decentralization. Evaluating the overlap of the company and family values, can be difficult, because the issues of definition and time, should be considered.

This is not a simple solution to assess the individual or organization values. F-PEC scale seeks the views of members of the CEO/owner-manager to the extent of overlapping between family and business values as well as family commitment to the business. However, the culture subscale seeks the views of the CEO/owner-manager, a strong case can be created to achieve the desires of other family members in order to achieve a larger image. On the one hand, exclusive reliance on self-reports of CEOs for the validation of a tool can create problems of bias. On the other hand, is not always possible to get multiple answers or to identify the right people. We believe that CEOs are sufficient to represent the business and families operations.

Hypothesis 3: culture and family values affect the family business. 


\subsection{Strategic Planning}

Strategic planning is the subject of many investigations. While intuitively it is assumed that there is a positive relationship between direct planning and development of the company, findings are inconsistent. Some researchers of entrepreneurship have questioned the value of strategic planning for new companies and small businesses. It is argued that the lack of internal flexibility was created by the constraints of organizational flexibility and ability to adapt to an imposed formal strategic planning. Instead, it is believed that a more informal and flexible approach to strategy (such as emerging and adaptive strategies) which gives the possibility to change and adaptation will enhance the performance. Furthermore, when we think about the limitations of resources, time and energy are required to develop strategic plans, some argue that the company leader's time may be spent better on the value creation activities. In family firms there is a risk that wealth preservation and conservative approaches was preferred, which acts against the needed strategic changes and prevent the growth of the company. In fact, the fastest growing family companies has been shown as the Proactive planning for the future and actively participate in strategic planning (Upton and others).

Hypothesis 4: Family Strategic Planning affects the family business.

It should be noted, Chrisman et al. (2003a, 2003b) suggested that without theory, there is no causal relationship, and the goal of helping family businesses to manage better their businesses, to conduct research. Each theory of the family firm should describe why family businesses are distinct, and how this uniqueness is created,

\section{Research Methodology}

This study utilized a non-experimental research - survey methods. The questionnaire consists of 5 parts. The first part of this study is designed to assess the demographic information such as gender, age and education. The second part of this form evaluates the measure of family power through the percent of family ownership, the percentage of family members in management team, the percentage of family in the Board items (See Appendix). In the third section, respondents answer the questions about family experience within a 5-point Likert scale with these items: how many generations of family have been the owners the company? How many generations were in management positions? How many generations have been active on the board? In the fourth part, respondents express their views about the culture in family businesses. These criteria are derived from the Klein's research (2001). This measure consists of 12 items that measured dimensions that are presented in the Appendix, where these items were integrated in the final model. In the last part of the questions about strategic plans of family businesses were asked and the impact of this criterion on the family business was measured. Target population for this study includes the qualified individuals in family firm, a sample of more than 211 people of the Golestan Company and "Shemshal Industrial Group were selected using random sampling and tested using affirmative factor analysis during 3 days in December 2014.

\subsection{The data analysis}

According to Table 1, alpha coefficients of all variables are higher than 0.70 and therefore questions have desirable reliability.

\section{Table 1}

The reliability calculation of research variables

\begin{tabular}{lcc}
\hline Dimensions & Number of Questions & Cronbach's alpha coefficients \\
\hline Family power & 3 & 0.776 \\
Family experience & 3 & 0.793 \\
Culture & 12 & 0.898 \\
Strategic Planning & 3 & 0.812 \\
\hline Total & 21 & 0.912 \\
\hline
\end{tabular}




\subsection{Descriptive Statistics}

As can be seen in Table 2, Most of the sample were female (66\%), aged between 20 and $30(50 \%)$, and those who have bachelor's degrees (73\%), respectively. In addition, 102 of them (48\%) had an experience less than 5 years. Other demographic characteristics are shown in Fig. 1.

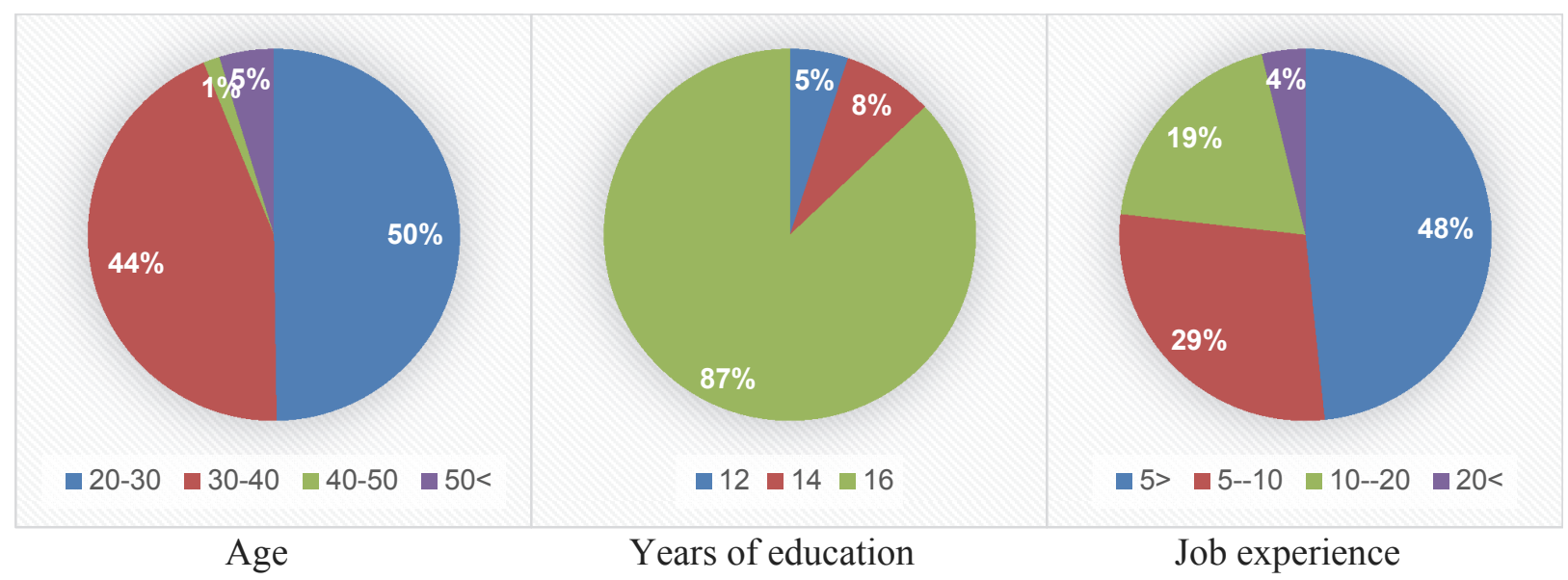

Fig. 1. Personal characteristics of the participants

Table 2

Descriptive statistics for research variables and Kolmogorov-Smirnov test

\begin{tabular}{lcccc}
\hline Variable & Mean & Standard deviation & Kolmogorov-Smirnov statistic & Significance level \\
\hline Family power & 3.64 & 0.81 & 1.3 & 0.07 \\
Family experience & 3.73 & 0.81 & 1.09 & 0.188 \\
Culture & 3.44 & 0.7 & 1.17 & 0.131 \\
Strategic Planning & 3.7 & 0.83 & 1.18 & 0.126 \\
\hline
\end{tabular}

According to Table 2, the family experience variable has the highest mean (of 3.73) and the culture variable has the least (3.44). The data dispersion of strategic planning variable is higher due to the higher standard deviation of (0.83). According to the Kolmogorov-Smirnov test results, the significance level for all the research variables is higher than 0.05 and this means confirmation of normal distribution hypothesis of the data. Therefore, the structural equation modeling and parametric tests can be used. Before examining the hypotheses, the software Spss 16 was used to identify correlations between variables and the Spearman correlation test was used for the ranking nature of data.

Table 3

Correlation between variables $(\mathrm{p}<0.01)$

\begin{tabular}{lcccc}
\hline Variable & Family power & Family experience & Culture & Strategic Planning \\
\hline Family power & 1 & $0.44 \mathrm{a}$ & $0.51 \mathrm{a}$ & $0.40 \mathrm{a}$ \\
Family experience & - & 1 & $0.38 \mathrm{a}$ & $0.53 \mathrm{a}$ \\
Culture & - & - & 1 & $0.36 \mathrm{a}$ \\
Strategic Planning & - & - & - & 1 \\
\hline
\end{tabular}

The results of correlation analysis showed that all research variables have statistically significant correlations (symbol " $a$ " in the table means Significant of relations in significant level of $0.01(\mathrm{p}<0.01)$. In addition, because the correlation coefficient is positive it can be said that there is positive and significant correlations between variables (Table 3 ). 


\subsection{Measurement models}

In Structural equation modeling, it is needed to test two models. The first model is a measurement model for each latent variable. Measurement model shows the factor loadings of observed variables (factors) for each latent variable. The common Fitting criteria in Measurement models for each of latent variables is presented in Table 5. Among fitting criteria, if the chi-square ratio to the degree of freedom is less than 2 , then the model has a proper fitting. The RMSEA index less than 0.05 is desirable. About the other indicators much closer to 1 is also more desirable. As can be seen, the major fitting criteria of all latent variables are in the good and acceptable range. In general, we can say that the sub-models of research are fitted properly.

Table 4

The fitting criteria of the measurement models of the Research latent variables

\begin{tabular}{crrrrrrrrrrr}
\hline Indicators & X2/df & RMSEA & NFI & CFI & IFI & RFI & GFI & PRATIO & PNFI & PCFI & AGFI \\
\hline Acceptable rate & $<2$ & $<0.05$ & $>0.9$ & $>0.9$ & $>0.9$ & $>0.9$ & $>0.9$ & $>0.5$ & $>0.5$ & $>0.5$ & $>0.9$ \\
Family power & 0.32 & 0 & 0.99 & 1 & 1 & 0.99 & 0.99 & 0.33 & 0.33 & 0.33 & 0.99 \\
Family experience & 0.19 & 0 & 0.99 & 1 & 1 & 0.99 & 0.99 & 0.33 & 0.33 & 0.33 & 0.99 \\
Culture & 0.008 & 0 & 1 & 1 & 1 & 1 & 1 & 0.33 & 0.33 & 0.33 & 1 \\
Strategic Planning & 0.03 & 0 & 1 & 1 & 1 & 1 & 1 & 0.33 & 0.33 & 0.33 & 0.99 \\
\hline
\end{tabular}

\subsection{Structural equation model}

After testing the measurement models now it is necessary to present the structural model that represents the relationship between latent variables. Using the structural model, we can evaluate the research hypotheses. The structural model is created using the Amos software version 18.

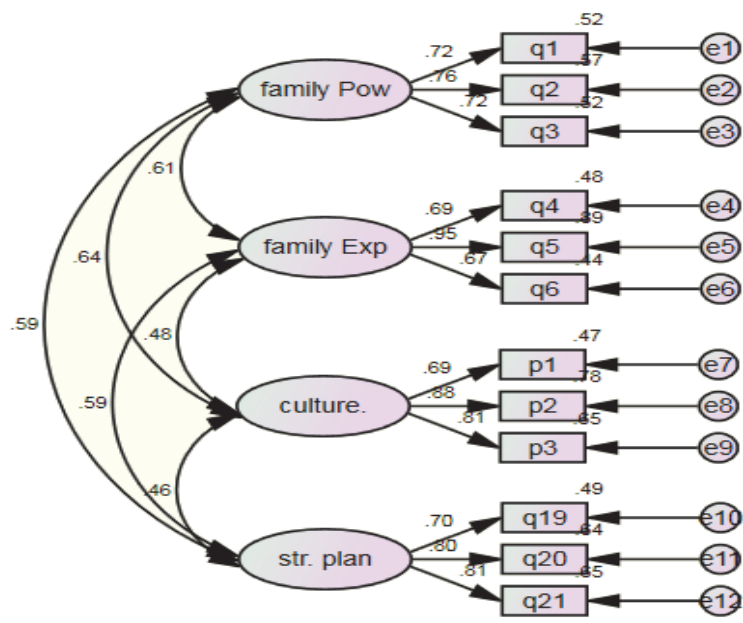

Fig. 2. The first order Confirmatory factor analysis

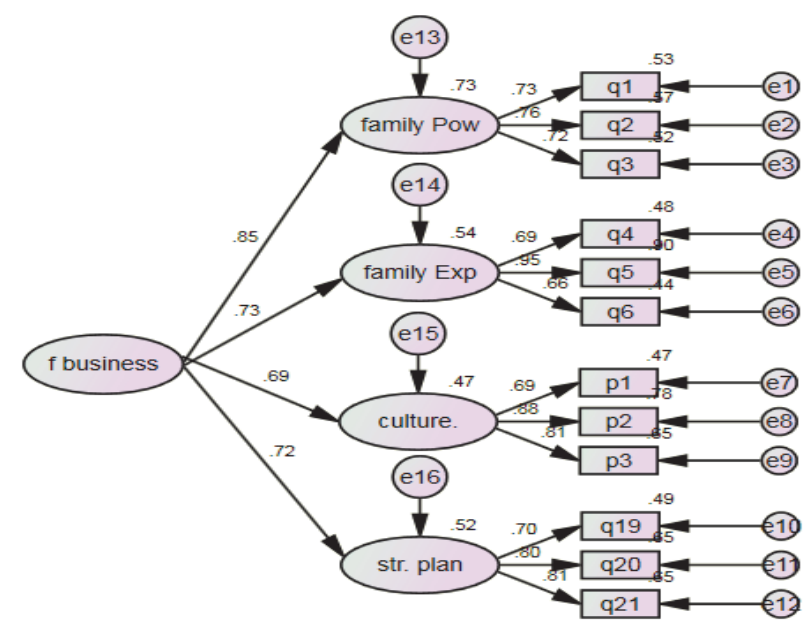

Fig. 3. The second order Confirmatory factor analysis

Table 5

The ultimate model fit indices

\begin{tabular}{|c|c|c|c|c|c|c|c|c|c|c|c|}
\hline Indicators & $\mathrm{X} 2 / \mathrm{df}$ & RMSEA & NFI & CFI & IFI & RFI & GFI & PRATIO & PNFI & PCFI & AGFI \\
\hline Acceptable rate & $<2$ & $<0.05$ & $>0.9$ & $>0.9$ & $>0.9$ & $>0.9$ & $>0.9$ & $>0.5$ & $>0.5$ & $>0.5$ & $>0.9$ \\
\hline Result & 2.48 & 0.08 & 0.9 & 0.93 & 0.93 & 0.86 & 0.91 & 0.72 & 0.65 & 0.68 & 0.86 \\
\hline
\end{tabular}


The Fitting criteria of the First order confirmatory factor analysis model in Table 5 shows the improper fitting of the model. So using the Amos corrective measures the model was reformed and the errors with the highest corrective indicators were related and indicators recovered as shown in Table 6.

Table 6

The fitting Indicators of the Research's first order Confirmatory-corrective model

\begin{tabular}{crrrrrrrrrrr}
\hline Indicators & X2/df & RMSEA & NFI & CFI & IFI & RFI & GFI & PRATIO & PNFI & PCFI & AGFI \\
\hline Acceptable rate & $<2$ & $<0.05$ & $>0.9$ & $>0.9$ & $>0.9$ & $>0.9$ & $>0.9$ & $>0.5$ & $>0.5$ & $>0.5$ & $>0.9$ \\
Total model & 1.3 & 0.038 & 0.95 & 0.98 & 0.98 & 0.92 & 0.96 & 0.62 & 0.59 & 0.61 & $>0.92$ \\
\hline
\end{tabular}

\subsection{Judgment about research relationships in the confirmatory factor analysis}

As shown in Table 7, the level of significance for all relations is between 0.05 and zero, $(* * *$ means $0.001>p$ ). So all four factors of the family power, family experience, strategic planning and culture play a crucial role in defining the variable of family business so that power has the higher rank than the rest of the variables and the culture has the least. In addition, according to factor analysis of the firstorder, all latent variables of research (family power, family experience, strategic planning and Culture) have a significant correlation.

Table 7

Estimation Indicators of Research model after correction

\begin{tabular}{|c|c|c|c|c|c|c|c|}
\hline & & & $\begin{array}{l}\text { non- } \\
\text { standard } \\
\text { Estimation }\end{array}$ & $\begin{array}{l}\text { standard } \\
\text { estimation } \\
\text { error }\end{array}$ & $\begin{array}{l}\text { Critical } \\
\text { ratio }\end{array}$ & $\begin{array}{l}\text { significance } \\
\text { level }\end{array}$ & $\begin{array}{l}\text { standard } \\
\text { estimation }\end{array}$ \\
\hline Family power & $\begin{array}{l}<-- \\
\end{array}$ & Family business & 1.000 & & & & .885 \\
\hline Family experience & $<---$ & Family business & .726 & .117 & 6.216 & $* * *$ & .692 \\
\hline Strategic Planning & $<---$ & Family business & .658 & .113 & 5.800 & $* * *$ & .764 \\
\hline Culture & $<---$ & Family business & .566 & .094 & 6.055 & $* * *$ & .623 \\
\hline q1 & $<---$ & Family power & 1.000 & & & & .730 \\
\hline q2 & $<---$ & Family power & 1.100 & .111 & 9.877 & $* * *$ & .800 \\
\hline q3 & $<---$ & Family power & .930 & .100 & 9.258 & $* * *$ & .687 \\
\hline q4 & $<---$ & Family experience & 1.000 & & & & .680 \\
\hline q5 & $<---$ & Family experience & 1.308 & .128 & 10.182 & $* * *$ & .972 \\
\hline q6 & $<---$ & Family experience & .951 & .108 & 8.781 & $* * *$ & .640 \\
\hline p1 & $<---$ & Culture & 1.000 & & & & .688 \\
\hline p2 & $<---$ & Culture & 1.247 & .118 & 10.568 & $* * *$ & .886 \\
\hline p3 & $<---$ & Culture & 1.076 & .105 & 10.214 & $* * *$ & .807 \\
\hline q19 & $<---$ & Strategic Planning & 1.000 & & & & .605 \\
\hline q20 & $<---$ & Strategic Planning & 1.185 & .126 & 9.434 & $* * *$ & .702 \\
\hline $\mathrm{q} 21$ & $<---$ & Strategic Planning & 1.683 & .215 & 7.840 & $* * *$ & .887 \\
\hline Family power & $<-->$ & Family experience & .278 & .053 & 5.268 & $* * *$ & .582 \\
\hline Family experience & $<-->$ & Culture & .171 & .037 & 4.559 & $* * *$ & .445 \\
\hline Culture & $<->>$ & Strategic Planning & .135 & .032 & 4.221 & $* * *$ & .425 \\
\hline Family experience & $<-->$ & Strategic Planning & .204 & .044 & 4.645 & $* * *$ & .559 \\
\hline Family power & $<-->$ & Strategic Planning & .267 & .050 & 5.303 & $* * *$ & .676 \\
\hline Family power & $<-->$ & Culture & .245 & .046 & 5.322 & $* * *$ & .590 \\
\hline
\end{tabular}

To test the research hypothesis that explains that each of the variables of the family power, family experience, strategic planning and culture influence the family business, $\mathrm{t}$ - test was used. According to Table 8, the test statistic value is higher than 1.96 for all variables, the upper and lower limit have the same sign and are positive and the significance level is 0.000 which is less than 0.05 . Therefore, we can say that the null hypothesis is rejected and the opposite hypothesis is confirmed for the testing variables. This means that the family power, the family experience, strategic planning and the culture affect the family business. As we can see, all means are higher than the mean of population $(=3)$, which indicates the beliefs of respondents about the high influence of each variable on the family business. 
Table 8

The results of t-test

\begin{tabular}{|c|c|c|c|c|c|c|c|}
\hline \multirow[t]{2}{*}{ Variable } & \multirow{2}{*}{$\begin{array}{l}\text { sample } \\
\text { size }\end{array}$} & \multirow[t]{2}{*}{ mean } & \multirow{2}{*}{$\begin{array}{l}\text { value of } \\
\text { the test } \\
\text { statistic }\end{array}$} & \multirow{2}{*}{$\begin{array}{l}\text { degrees } \\
\text { of } \\
\text { freedom }\end{array}$} & \multirow{2}{*}{$\begin{array}{c}\text { significance } \\
\text { level }\end{array}$} & \multicolumn{2}{|c|}{$\begin{array}{c}\text { Mean confidence interval } \\
\text { with } 95 \% \text { CI }\end{array}$} \\
\hline & & & & & & upper limit & lower limit \\
\hline Family power & 211 & 3.64 & 11.39 & 210 & 0 & 0.749 & 0.528 \\
\hline Family experience & 211 & 3.73 & 13.15 & 210 & 0 & 0.841 & 0.622 \\
\hline Strategic Planning & 211 & 3.7 & 12.29 & 210 & 0 & 0.812 & 0.586 \\
\hline Culture & 211 & 3.44 & 9.06 & 210 & 0 & 0.532 & 0.342 \\
\hline
\end{tabular}

\section{Conclusion}

The results show that all four factors of family power, family experience, strategic planning and culture play a crucial role in defining and explaining the variable of family business so that the family power has the higher rank than other variables and culture has the lowest. Also according to the statistical results and the answers of the respondents it was concluded that the strategic planning has direct relationship with the family business and has correlation with the other three dimensions and ultimately none of the dimensions were removed from the model and the relationships were confirmed. The results of the research are important that they provide empirical support for the validity and reliability of the F-PEC scale. Since they get theoretical support and have been widely used (e.g. Klein, 2003) and have been approved by the researchers.

\section{Acknowledgement}

The authors would like to thank the anonymous referees for constructive comments on earlier version of this paper.

\section{References}

Anderson, R. C., \& Reeb, D. M. (2003). Founding-family ownership and firm performance: evidence from the S\&P 500. The Journal of Finance, 58(3), 1301-1328.

Astrachan, J. H., Klein, S. B., \& Smyrnios, K. X. (2002). The F-PEC scale of family influence: A proposal for solving the family business definition problem. Family business review, 15(1), 45-58.

Bird, B., Welsch, H., Astrachan, J. H., \& Pistrui, D. (2002). Family business research: The evolution of an academic field. Family Business Review, 15(4), 337-350.

Birley, S., \& Pleitner, H. J. (2001). Owner-manager attitudes to family and business issues: A 16 country study. Entrepreneurship Theory and Practice, 26(2), 63-76.

Carlock, R., \& Ward, J. (2001). Strategic planning for the family business: Parallel planning to unify the family and business. Springer.

Cabrera-Suárez, K., De Saá-Pérez, P., \& García-Almeida, D. (2001). The succession process from a resource-and knowledge-based view of the family firm. Family Business Review, 14(1), 37-46.

Chrisman, J. J., Chua, J. H., \& Sharma, P. (2003). Current trends and future directions in family business management studies: Toward a theory of the family firm. Coleman white paper series, 4(1), $1-63$.

Chrisman, J.J., Chua, J.H., \& Steier, L.P. (2003a). An introduction to theories of family business. Journal of Business Venturing, 18, 441-448.

Chrisman, J.J., Chua, J.H., \& Zahra, S.A. (2003b). Creating wealth in family firms through managing resources: Comments and extensions. Entrepreneurship, Theory \& Practice, 27(4), 359-365.

Chua, J.H., Chrisman, J.J., \& Sharma, P. (1999). Defining the family business by behavior. Entrepreneurship, Theory \& Practice, 23(4), 19-39. 
Faccio, M. \& Lang, L. (2002). The ultimate ownership of Western European corporations. Journal of Financial Economics, 65(3), 365-395.

Flören, R.H. (2002). Crown princes in the clay: An empirical study on the tackling of succession challenges in Dutch family farms. Dissertation, Universiteit Nyenrode.

Heck, R.K.Z. \& Scannell Trent, E. (1999). The prevalence of family business from a household sample. Family Business Review, 12(3), 209-224.

Johannisson, B. \& Huse, M. (2000). Recruiting outside board members in the small family business: An ideological challenge. Entrepreneurship and Regional Development, 12(4), 353-378.

Kayser, G. \& Wallau, F. (2002). Industrial family businesses in Germany: Situation and future. Family Business Review, 15(2), 111-115.

Klein, S. B. (2000). Family businesses in Germany: Significance and structure. Family Business Review, 13(3), 157-181.

Klein, S.B. \& Blondel, C. (2002). Ownership structure of the 250 largest listed companies in Germany. INSEAD working paper 2002/123/IIFE.

Stewart, A. (2003). Help one another, use one another: Toward an anthropology of family business. Entrepreneurship, Theory \& Practice, 27(4), 383-396.

Witt, P. (2003). Corporate governance systeme im Wettbewerb, Wiesbaden: Deutscher Universitätsverlag.

Whyte, M.K. (1995). The social roots of China's economic development. The China Quarterly, 144, 900-1019.

\section{Appendix}

\section{Variables and Items}

\begin{tabular}{ll}
\hline row & Description \\
\hline Family power & \\
\hline 1 & family ownership Percent of stocks \\
\% Of the family members in management team \\
\% of The family members in the Board
\end{tabular}


(C) 2018 by the authors; licensee Growing Science, Canada. This is an open access article distributed under the terms and conditions of the Creative Commons Attribution (CC-BY) license (http://creativecommons.org/licenses/by/4.0/). 